\title{
El Canal Beagle y consulta popular en 1984. Relaciones internacionales y política interna argentina*
}

\section{The Beagle Channel and a referendum in 1984: International Relations and domestic politics in Argentina}

\author{
María Cecilia Míguez ${ }^{* *}$ \\ Instituto de Estudios Económicos, Históricos, Sociales e Internacionales \\ Universidad de Buenos Aires, CONICET, \\ Argentina.
}

Recibido: 14 de septiembre de 2017. Aprobado: 29 de agosto de 2018.

\section{Resumen}

En el contexto de la reciente vuelta a la democracia en la Argentina, y a menos de un año de la asunción de Raúl Alfonsín, se realizó en 1984 una consulta popular no vinculante respecto de una propuesta de paz con Chile, referida a la cuestión del canal Beagle. Consideramos que se trata de un hecho que es necesario revisar, ya que la población fue convocada a votar respecto de un conflicto internacional, fenómeno poco frecuente. Ello conllevó intensos debates y complejos alineamientos en los partidos políticos. Parece interesante analizar cómo se entrecruzan las posiciones internacionales, el escenario de disputa entre las potencias y la dinámica política interna, tan compleja en el período. Por eso, identificaremos en este artículo las distintas posiciones de los partidos políticos, corporaciones y fuerzas políticas más representativas, para analizar en qué medida los debates respondieron a una evaluación de la circunstancia internacional y/o a la compleja dinámica política interna. Es objetivo de este trabajo abordar los condicionantes internos de la política internacional, variables muchas

* El presente artículo forma parte del Proyecto PIP CONICET Programación Científica del Consejo Nacional de Investigaciones Científicas y Técnicas 2015-2107, dirigido por la autora y titulado "Los condicionantes internos de la inserción internacional argentina. Presiones, debates y movilizaciones en torno a la política exterior desde la década de 1960 hasta la actualidad"; y del Proyecto UBACyT, "Política exterior, inserción económica internacional y movilización popular (1966-2016)", Programación Científica de la Secretaría de Ciencia y Tecnología de la Universidad de Buenos Aires, ambos desarrollados en el Instituto de Estudios Históricos Económicos Sociales e Internacionales (IDEHESI-UBA-CONICET).

*** Doctora en Ciencias Sociales (FSOC-UBA), especialista en Historia Económica y Políticas Económicas (FCE-UBA); licenciada en Ciencia Política (UBA); investigadora adjunta de CONICET. Investigadora del IDEHESI, Instituto de Estudios Económicos, Históricos, Sociales e Internacionales, UBA, CONICET. Sánchez de Bustamante 217313 A, cod. postal 1425. Ciudad de Buenos Aires. Correo electrónico: mmccmiguez@gmail.com 
veces descuidadas a la hora de interpretar la política exterior de los gobiernos dictatoriales o democráticos.

Palabras clave: canal Beagle, consulta popular, política exterior.

\begin{abstract}
Within the context of the recent return to democracy in Argentina, and less than a year after Raúl Alfonsín was elected president, a non-binding referendum over the Beagle Channel was held in 1984 regarding a peace proposal with Chile. We consider that such an event, of a population being asked to vote regarding an international conflict, should be examined, given it is such a rare phenomenon. The referendum led to intense debates and complex alignments between political parties. It is also interesting to analyze how international positions became intertwined, in an environment of disputes between rival powers, and internal political dynamics, all of which were complex during the period in question. We will therefore identify in this article the different positions of political parties, corporations and the most representative political forces, in order to analyze as to what extent the debates responded to an assessment of the international circumstance and/or the complexity of domestic political dynamics. The aim of this paper is to address the domestic determinants of international politics, which are variables that are often neglected when interpreting the foreign policy of dictatorial or democratic governments.
\end{abstract}

Keywords: Beagle channel, referendum, foreign policy.

\title{
Introducción
}

En el contexto de la reciente vuelta a la democracia en Argentina, y a menos de un año de la asunción de Raúl Alfonsín, perteneciente a la Unión Cívica Radical (UCR), se realizó en 1984 una consulta popular no vinculante respecto de una propuesta de paz con Chile, referida a la cuestión del canal Beagle. El diferendo consistía en un desacuerdo entre Argentina y su país vecino, Chile, sobre la determinación de la traza de la boca oriental del canal, que afectaba por tanto la soberanía de las islas ubicadas dentro y al sur del canal, al este del meridiano del cabo de Hornos y sus espacios marítimos adyacentes. Es notable que los primeros antecedentes del conflicto se remontan a 1888 - a solo siete años de la firma del tratado de límites entre Argentina y Chile- y que durante la última dictadura militar los países citados se encontraron al borde de un enfrentamiento bélico por este conflicto, en noviembre 
de 1978. La intervención de la máxima autoridad de la Iglesia católica, el Papa Juan Pablo II, fue relevante para evitar la guerra y abrir una nueva propuesta de paz.

Lo singular fue que en noviembre de 1984, el oficialismo llamó, como parte de una estrategia de legitimación política, a votar a favor de la mediación papal presentada en diciembre de 1980. Consideramos que se trata de un hecho que es necesario revisitar, ya que la población fue convocada a votar respecto de un conflicto internacional, fenómeno poco frecuente. Ello conllevó interesantes debates y argumentaciones, y complejos alineamientos. Parece interesante analizar cómo se entrecruzan las posiciones internacionales, el escenario de disputa entre las potencias y la dinámica política interna, tan compleja en el período. Por eso, identificaremos en este artículo las distintas posiciones de los partidos políticos, corporaciones y fuerzas políticas más representativas, para analizar en qué medida los debates respondieron a una evaluación de la circunstancia internacional y/o a una compleja dinámica política interna. Es objetivo de este trabajo abordar los condicionantes internos de la política internacional, variables muchas veces descuidadas a la hora de interpretar la política exterior de los gobiernos dictatoriales o democráticos.

El caso de referéndum sobre el Beagle demostró que las distintas fuerzas políticas definieron su posición en referencia a variables distintas -y, en su mayoría, de carácter doméstico-, entre las que se cuentan: la dinámica política interna entre oficialismo y oposición, el peso político del Vaticano, el escenario de la disputa entre las potencias, la hipótesis de conflicto y la rivalidad con Chile, e incluso la vinculación con la cuestión de la soberanía de las islas Malvinas y el reciente conflicto bélico.

El aporte particular de este artículo es también la aplicación de un enfoque teóricometodológico cualitativo y multidisciplinario para el análisis del comportamiento de sectores internos con respecto a la política exterior en el período. Partimos de la vinculación entre el sistema político local y las élites políticas, la política económica doméstica y el sistema internacional, así como de la necesidad de utilizar un enfoque histórico y global para el estudio de las relaciones internacionales. Para ello se requiere entrecruzar fuentes diversas, primarias y secundarias, que incluyen desde un amplio corpus periodístico hasta documentación de organismos de inteligencia. Se trata de incorporar a los análisis de la política exterior la cuestión central de la legitimidad política, variable a tener en cuenta en los gobiernos democráticos, especialmente aquellos que buscan apelar al apoyo de amplias mayorías populares. El objetivo es poner de manifiesto qué percepción tenían los actores de los acontecimientos y cómo se relacionaban estos con la política exterior, utilizando como unidad de análisis los partidos políticos, corrientes ideológicas e individuos representativos de ellas. 


\section{La política exterior del gobierno de Raúl Alfonsín}

En las elecciones presidenciales de 1983, Alfonsín se impuso sobre el justicialista Ítalo Luder. Con un discurso más cercano a la socialdemocracia europea, el radicalismo lograba construir una imagen de partido defensor de la democracia y de las instituciones, que borraba la complicidad de muchos de sus dirigentes con los distintos gobiernos de facto en Argentina. Durante la campaña presidencial de 1983, el candidato radical había denunciado públicamente la existencia de un pacto entre quien fuera en ese momento comandante en jefe del Ejército, general Cristino Nicolaides, y Lorenzo Miguel -dirigente sindical de la Unión Obrera Metalúrgica (UOM) y principal apoyo de Luder- para no revisar las violaciones de los derechos humanos cometidas durante la dictadura, mantener sin variantes a la cúpula del Ejército en el próximo gobierno y evitar la intervención del poder constitucional en la reorganización de las Fuerzas Armadas en caso de que triunfara el candidato peronista. Esa situación contribuyó a desprestigiar el justicialismo y el triunfo del candidato radical.

Alfonsín representaba a toda una línea política nucleada en el Movimiento de Renovación y Cambio (MRyC), que sistemáticamente se había opuesto al gobierno militar, y supo leer la demanda social de recuperación institucional. Sin embargo, esto no anula el hecho de que el Partido Radical fue el que más funcionarios civiles aportó a las sucesivas dictaduras militares a lo largo de la historia argentina, teniendo posiciones conciliatorias y condescendientes con varias de ellas, y que, tal como afirma Alberto Bonnet, "medio siglo de participación en administraciones fraudulentas, colaboración con las dictaduras militares y ejercicio de gobiernos resultantes de elecciones con proscripciones impide que la UCR pueda ser asociada de manera privilegiada a los valores democráticos" (Bonnet, 2007, p. 87). Lo cierto es que la posición que el líder había adoptado respecto de la guerra de las Malvinas, acontecida entre abril y junio de 1982, también era importante a la hora de la elección. Si bien durante los días cercanos a la fecha de recuperación de las islas, Alfonsín había apoyado la iniciativa, decidió no participar de la delegación que se trasladó hasta allí para asistir a la asunción del nuevo gobernador militar de las islas, el general Mario Benjamín Menéndez. De ese modo se diferenciaba de varios dirigentes políticos que integraban la Multipartidaria. ${ }^{1}$ Desde ese momento, Alfonsín se opuso al accionar del gobierno militar, poniendo el énfasis en que se trataba de un modo de fortalecer la dictadura. Asimismo, a lo largo del conflicto, había reclamado a la junta militar exigiendo que brindara información verídica. Luego de la derrota, el líder radical logró capitalizar esas posiciones para presentarse como símbolo de una nueva democracia. El amplio porcentaje con que el presidente electo había triunfado

$1 \quad$ La Multipartidaria fue una instancia de acción política conjunta creada en 1981 e integrada por la Unión Cívica Radical (UCR), el Partido Justicialista (PJ), el Partido Intransigente (PI), el Demócrata Cristiano (DC) y el Movimiento de Integración y Desarrollo (MID). Tuvo como objetivo presionar a la dictadura militar (1976-1983) para que abandonara el poder y se estableciera un régimen democrático. Se constituyó el 14 de julio de 1981 y se disolvió luego de las elecciones de 1983. 
traducía un alto nivel de apoyo y, sobre todo, expectativas. El conocido lema de campaña "Con la democracia se come, se cura y se educa" resumía la necesidad de recuperar un rumbo de desarrollo y bienestar. Dichas expectativas se verían frustradas muy pronto.

La política internacional tuvo, en los inicios, el objetivo de "reinsertar" a Argentina en el mundo occidental a partir de la recuperación de la democracia, por lo tanto, una de las estrategias centrales fue la búsqueda de apoyos al nuevo régimen por parte de los gobiernos europeos -particularmente los de orientación socialdemócrata- y de los países de la región. Esta orientación tenía como función no solo apuntar a una nueva inserción internacional, sino también operar como elemento defensivo en el plano interno para resguardar la transición al régimen democrático.

En los primeros discursos, América Latina aparecía jerarquizada como principal socio posible respecto del resto de los países. Así, autonomía e integración regional se encontraban entre los primeros objetivos de la política exterior (Caputo cit en Reficco, 1996). La legitimación discursiva de la política exterior estaba regida por una serie de principios vinculados al paradigma de la autonomía y, por lo tanto, a la afirmación de la ubicación de Argentina en el Tercer Mundo. Así lo afirmaba el propio Alfonsín:

Nuestra acción se basará, en consecuencia, en un respeto sincero a los propósitos y principios del derecho y la práctica internacionales, la no intervención y la no injerencia en los asuntos internos y externos de los Estados, el pluralismo político, la defensa de la soberanía nacional e integridad territorial, la solución pacífica de las controversias, la eliminación del colonialismo y de toda otra forma de dominación extranjera, la igualdad de razas, el respeto a todo credo o religión, la vigencia auténtica de los derechos humanos y el desarrollo económico. (1984, pp. 15-16)

La búsqueda de soluciones pacíficas a las controversias quedó reflejada en la política para la solución del conflicto por el canal Beagle. Tal como desarrollaremos aquí, ante la propuesta mediadora de Juan Pablo II y ante la negativa de parte de la oposición legislativa justicialista a apoyar la firma de un tratado que la aceptara, Alfonsín llamó a un plebiscito para consultar a la opinión pública, en el que triunfó la voluntad de aprobar el laudo papal. Esto permitió que el Congreso ratificara en 1984 el Tratado de Paz y Amistad entre Argentina y Chile, solucionando el conflicto que estuvo a punto de generar una guerra entre los países hermanos en 1978.

El fracaso de la negociación de la deuda externa y de la conformación de un Club de Deudores, el estancamiento de las negociaciones por la soberanía de las islas Malvinas en la reunión de Berna y la aceptación de la intervención del Fondo Monetario en la formulación 
del plan económico redundaron en una nueva orientación económica y política (Míguez, 2013). La nueva dirección de la inserción internacional fue bautizada por la cancillería como el "giro realista" de la gestión. Los hitos fueron el cambio de posición respecto de la deuda externa y en especial una segunda visita que Alfonsín realizó a Estados Unidos, en marzo de 1985, aquella misma de los famosos discursos de los jardines. Allí anunció la necesidad de reformar el Estado y privatizar empresas públicas, declarando la intención de someter a licitación 165 áreas petrolíferas, en lo que se conoció como Plan Houston. El carácter "realista" del giro hacía referencia a cierto abandono del idealismo como paradigma teórico en el sustento de la diplomacia. Por lo tanto, hubo una reformulación de los objetivos de política internacional, tal como lo afirmó el canciller Caputo, cuando modificó el orden de las prioridades: "a los Estados Unidos, a América Latina, a Europa Occidental y a los países en desarrollo" (Discurso de Dante Caputo en el almuerzo anual de la Cámara de Anunciantes, 1984, p. 3).

En síntesis, y para inscribir el referéndum del Beagle en el contexto de la política exterior, durante los dos primeros años del gobierno se pusieron rápidamente a prueba las expectativas y límites de una propuesta que pretendía establecer políticas de relativa autonomía respecto de Estados Unidos, sobre la base de las buenas relaciones con la socialdemocracia europea y con la Unión Soviética - principal comprador de los productos agroexportables hasta 1986. En cuanto a las cuestiones más puramente políticas, el gobierno de Alfonsín buscó retomar el perfil históricamente democrático de la política internacional argentina (compromiso con la solución pacífica de controversias, respeto por la autodeterminación de los pueblos y la no injerencia de las potencias en los asuntos internos), lo que se evidenció en la posición del gobierno adoptada en el caso del conflicto de Nicaragua y en la participación en el Grupo Contadora, su voto en la Organización de Naciones Unidas, su negativa a firmar el Tratado de No Proliferación Nuclear y a la desactivación del misil Cóndor II, y en la permanencia en el Movimiento de Países no Alineados (Míguez, 2013).

Sin embargo, desde fines de 1984 hubo un acercamiento paulatino a los dictámenes de las grandes potencias y de los organismos multilaterales de crédito, en el plano de la política económica exterior; paralelamente, persistieron políticas estratégicas o diplomáticas de alto perfil, mediante las cuales se buscaba actuar con cierto margen de autonomía, en especial respecto de Estados Unidos (Paradiso, 1993). Al mismo tiempo, y como anticipábamos, al menos hasta 1986, lo fundamental de las exportaciones agropecuarias seguía dependiendo del mercado soviético - en los marcos de la aún vigente "guerra fría"-, lo que explicaría en cierta medida la no suscripción por parte del gobierno del reclamo internacional de cese de la ocupación rusa de Afganistán. 
A partir de 1985, la tensión entre, por un lado, el "giro realista" y el ajuste económico acordado con el FMI en oportunidad del Plan Austral, y por el otro, la política de alto perfil, le generó acusaciones provenientes de distintos frentes. Uno de esos frentes incluía a quienes criticaban la política económica partiendo de argumentos vinculados al nacionalismo económico y la defensa de la industrialización y el mercado interno, y el otro, a quienes bregaban por el abandono del alto perfil político, caracterizándolo peyorativamente de "principismo". Resumiendo, la política exterior llevada a cabo por el gobierno de Alfonsín logró mantener márgenes de autonomía respecto de Estados Unidos, sobre la base de sus buenas relaciones con la Unión Soviética, con Europa Occidental y con otros países latinoamericanos. Ahora bien, lo hizo especialmente en el área político-diplomática y estratégico-militar de la política exterior, y no en la dimensión económica.

En cuanto al contexto del sistema político, la primera etapa del gobierno de Alfonsín fue caracterizada por Hernán Fair (2009) como una etapa de lógica pendular entre la confrontación con el principal partido de oposición (el PJ) y con las corporaciones, y la concertación. Lo cierto es que la distribución de poder resultante de las elecciones dejó configurado un parlamento con mayoría radical en diputados y mayoría peronista en senadores (Fair, 2009). La confrontación más importante fue respecto de la Ley de Reordenamiento Sindical, conocida como Ley Mucci. Fue en diciembre de 1983, y le permitió al justicialismo reunificar fuerzas y diferenciarse del gobierno. La respuesta del oficialismo fue que a partir de ese momento las decisiones que pudieran resultar conflictivas se tomarían fuera del ámbito legislativo (De Riz y Smulovitz, 1991). La cuestión del Plan Austral (1985), por ejemplo, también sería definida por fuera del ámbito parlamentario. Ese escenario contribuyó a la decisión de plebiscitar la decisión de política exterior, un hecho atípico en Argentina y en general. Se reforzó el carácter presidencialista de la política internacional. Sin embargo, a pesar de que esas prácticas intentaban evitar el conflicto o el bloqueo interpartidario, ese poder presidencial se demostraría cada vez más aislado y, por lo tanto, frágil. Tal como afirma Fair (2009), la dimensión de la crisis restringirá, a su vez, la capacidad del presidente de tomar decisiones.

\section{Breves antecedentes del conflicto}

Uno de los hitos que fueron jalonando la larga historia del conflicto por el canal ocurrió el 22 de junio de 1971, cuando ambos países firmaron un compromiso de arbitraje, confiando la cuestión a una corte arbitral conformada por cinco jueces de la Corte Internacional de Justicia de La Haya, la cual debía someter su decisión a la reina de Gran Bretaña. Finalmente, varios años después, el laudo arbitral de Gran Bretaña fue comunicado a ambos países en mayo de 1977: la resolución dejaba para Chile las islas Picton, Lennox y Nueva, y todas las 
islas e islotes próximos a ellas. En esa oportunidad, luego de intentar una negociación secreta con Chile que fracasó, el gobierno de la dictadura militar argentina declaró unilateralmente su nulidad. Russell (1990) explica que existían posiciones más moderadas, proclives al acuerdo, pero que tuvieron más fuerza las que definieron el rechazo, posición sostenida por el general Osiris Villegas. En ese sentido, la dictadura de Pinochet aparentaba una mayor "unidad de mando" (Tapia, 1997).

El proceso de negociaciones que incluyó una significativa reunión presidencial en enero de 1978 en el aeropuerto militar Plumerillo, provincia de Mendoza, y luego otra en febrero, en Puerto Montt, ha sido detalladamente relatado por el coronel Ernesto Videla Cifuentes (2008), protagonista y jefe de la delegación chilena en la Santa Sede. Luego vendría el punto más álgido del enfrentamiento, en diciembre de 1978, cuando las Fuerzas Armadas argentinas estaban dispuestas a iniciar la denominada Operación Soberanía, para ocupar el territorio que se encontraba en litigio. Cabe destacar que a través de diversos mecanismos, tal como ha estudiado Pablo Lacoste (2004), las decisiones del gobierno de facto argentino, al rechazar el laudo arbitral primero y al endurecer su posición hasta colocar al país al borde de la guerra después, contaron con el respaldo de amplios sectores civiles, particularmente empresarios.

Pero esa escalada de amenaza bélica encontró un freno. El clásico trabajo de Archibaldo Lanús (1984) da cuenta de la existencia de una misión secreta a Estados Unidos, que culminó en una reunión decisiva en la Casa Blanca con Bob Pastor, asesor para asuntos interamericanos del presidente Carter. Lanús afirma que el embajador White, representante de Estados Unidos en la Santa Sede, recibió instrucciones de su gobierno para solicitar al Vaticano su intervención urgente. Russell, en su también clásico y fundamental artículo, analiza la fragmentación del proceso decisorio que caracterizó esas negociaciones, ya que, de acuerdo a lo que plantea el autor, Videla y el canciller Carlos Washington Pastor pusieron en marcha una misión secreta destinada a contactar a Estados Unidos, la Unión Soviética y el Vaticano con la finalidad de flexibilizar en alguna medida la posición de Chile para refrenar las posiciones más duras de algunos sectores de las Fuerzas Armadas (Russell, 1990).

Esas gestiones culminaron en que el Papa Juan Pablo II anunciara hacia diciembre de 1978 el envío de un delegado papal. Así se logró evitar el conflicto bélico y el 26 de diciembre llegó al país el cardenal Antonio Samoré, quien actuaría de mediador hasta su fallecimiento. En enero de 1979, los representantes de Argentina y Chile, reunidos en Montevideo, solicitaron formalmente la mediación de la Santa Sede, suscribiendo el Acta de Montevideo, y un acuerdo que los comprometía a no hacer uso de la fuerza ni a amenazar con ello. Ese acuerdo no estuvo exento del descontento entre sectores como el liderado por Menéndez, que 
de acuerdo a lo planteado por Russell (1990), incluso intentó evitar el vuelo del canciller Pastor a Montevideo, donde se reuniría con Samoré. La continuidad de la situación de tensión en la frontera se debió asimismo a las internas entre el sector videlista, más proclive a la mediación, y la línea de la Armada y los "halcones" del Ejército, dispuestos a avanzar en el enfrentamiento.

En un documento de la CIA del 8 diciembre de 1979 se afirma que las Fuerzas Armadas argentinas estaban preparadas para iniciar hostilidades hacia mediados de ese mes si Chile no hacía concesiones sustanciales en la reunión de Ministros de Relaciones Exteriores a celebrarse el día 12. Asimismo, se indica que "las líneas más duras de la comandancia militar son altamente críticas del Presidente Videla en sus esfuerzos para alcanzar una solución pacífica, y el Presidente probablemente está perdiendo el control de la situación" (CIA Records, 1979, s/n).

En el mes de diciembre de 1980, el Sumo Pontífice entregó a las delegaciones diplomáticas argentina y chilena -conducidas respectivamente por el canciller Carlos W. Pastor y René Rojas Galdames- la propuesta de paz, pero en esa oportunidad se conoció solamente un contenido parcial. Eso provocó la condena de parte de varios sectores políticos en Argentina, que calificaron la situación como de "diplomacia secreta" (La propuesta papal de Juan Pablo II, 1984, p. 4). Fue aceptada el 8 de enero de 1981 por Chile y objetada por Argentina, que continuaba mostrando disconformidad (Benadava, 1999). En marzo de 1981, la dictadura argentina respondió con un memorándum que rechazaba la propuesta de paz y completó esa acción en el mes de enero de 1982 con una denuncia unilateral del tratado suscrito en 1972 (Un arbitraje nulo de nulidad absoluta, 1984).

A partir de abril de 1982, las posiciones respecto de la cuestión del Beagle y el conflicto de Malvinas se entrecruzarían. La dictadura apostaba a que un triunfo en las islas garantizaría también el predominio de su posición en el conflicto por el canal. En medio de la Guerra de Malvinas, el 23 de abril de 1982, Juan Pablo II llamó a ambos gobiernos a lograr un tratado permanente de paz y amistad.

Durante la campaña electoral, la solución pacífica en el marco de la mediación papal con respeto al principio bioceánico eran temas presentes en la plataforma del radicalismo. Al mismo tiempo, la Multipartidaria había proclamado hacia agosto de 1983 su apoyo a la intervención del Vaticano. Luego de las elecciones y del triunfo de Alfonsín, esa política se fue profundizando.

Como resultado de las negociaciones, ya en un contexto democrático, el 23 de enero de 1984 los cancilleres argentino y chileno firmaron una declaración de paz en la Santa Sede, 
conocida como Declaración de Paz y Amistad, dando paso a una última etapa de las negociaciones. Al día siguiente, la prensa publicaba el texto de esa declaración, pero las condiciones del acuerdo no se conocerían por varios meses (Argentina y Chile firmaron en Roma la declaración de Paz y Amistad, 1984). En esa oportunidad, Caputo afirmó la importancia de la paz dentro de los objetivos para el gobierno democrático, "paz que contribuye a desalentar toda expectativa de conflicto y en sentido lineal toda hipótesis bélica" (Optimismo de Caputo por la solución con Chile, 1984, p. 1). Trazó además una vinculación con la cuestión de las islas Malvinas, cuando dijo que las críticas al gobierno eran minoritarias, pues tras la guerra de las Malvinas "los argentinos han dejado de entender a la palabra paz como una palabra abstracta" $y$, por el contrario, "han comprendido el significado de la paz cuando tocaron el significado de la guerra" (Optimismo de Caputo..., 1984, pp. 1 y 4).

Isaac Rojas y Roberto Marcelo Levingston, ambos retirados pero referentes políticos de corrientes dentro de las Fuerzas Armadas, habían sido consultados por el diario La Nación a comienzos del año 1984, cuando Alfonsín y sus colaboradores estaban retomando el diálogo con Chile para firmar la paz. Cabe recordar que Isaac Rojas fue un almirante dentro de la coalición golpista contra Juan Domingo Perón en 1955, protagonista de los bombardeos a la población civil en Plaza de Mayo del 16 de septiembre de ese año, y vicepresidente de facto de la dictadura que se autoproclamó Revolución Libertadora (1956-1958). Levingston se había desempeñado como presidente durante la dictadura cívico-militar autodenominada Revolución Argentina, entre 1970 y 1971.

Rojas se opuso abiertamente a cualquier negociación con Chile que implicara resignar la zona en litigio sin un previo debate amplio del tema, y criticó la posición de Alfonsín durante la campaña electoral de reconocer ante la prensa chilena que las islas Picton, Nueva y Lennox se encontraban en el canal Beagle, apoyando así la tesis del país vecino (Oposición a un arreglo con Chile sin que haya debate previo, 1984).

Luego de la efectiva firma de la declaración de "Inalterable Paz y Amistad Perpetua" del 23 de enero, Rojas fue contundente al reiterar la misma posición y afirmó: "este tratado, en el fondo, oculta las verdaderas intenciones del gobierno argentino, que son la de ceder a Chile las islas usurpadas por este país, y que se encuentran en pleno Océano Atlántico", señalando que eso contravenía los Tratados de 1881, de 1893 y la aclaración de 1902, y que se estaba "preparando a la opinión pública para que capte esta entrega que significaría una nueva mutilación del territorio argentino" (Apreciaciones del almirante Rojas, 1984, p. 2). Levingston, por su parte, dijo que no entendía el optimismo del gobierno, ya que la única posición honorable de Argentina era la de respetar el principio bioceánico, asegurando el límite en tierras insulares hasta cabo de Hornos, y que en principio la mediación papal 
mantenía de hecho el laudo arbitral británico, que había afirmado la soberanía chilena de las tres islas en disputa (El compromiso de paz con Chile, respaldo y críticas, 1984).

El argumento central del gobierno, y en especial del canciller Caputo, era el rechazo a la "política de poder", es decir, a la mirada de la geopolítica vinculada a un tipo de nacionalismo chauvinista que caracterizaba a la formación de los militares argentinos. En oportunidad del discurso en la Santa Sede, en enero de 1984, el canciller afirmó: "Creemos también que lamentablemente debajo del rechazo de las soluciones pacíficas subyace la tentación de la política de poder. Este es un peligro que debemos evitar" (Dante Caputo: rechazo a la política de poder, 1984, p. 3).

El oficialismo utilizaba como argumento válido y lógicamente a favor, la cuestión de que los grupos ultranacionalistas que aún dudaban de los beneficios de la democracia alimentaban el conflicto con Chile. Por lo tanto, era objetivo del radicalismo no solamente dar por cerrado el conflicto, sino también "reducir el espacio de los grupos ultranacionalistas, siempre dispuestos a utilizar las cuestiones territoriales para sus propios fines políticos" (Russell, 1990, p. 55).

En el Parlamento, el senador radical Adolfo Gass, uno de los principales defensores públicos del acuerdo, sería protagonista de los debates que surgirían posteriormente. El senador justicialista Eduardo Duhalde calificó en esa oportunidad como positivo el compromiso firmado, reafirmando al mismo tiempo la potestad del Congreso Nacional de aceptar o rechazar luego el tratado al que se arribara (Resonancia favorable en el Senado nacional, 1984).

Arturo Frondizi (expresidente argentino y líder de la corriente desarrollista) y María Estela Martínez de Perón (expresidenta, viuda de Perón y jefa del Justicialismo) también tuvieron un rol a favor del acuerdo, en especial a través del contacto con el nuncio apostólico monseñor Ubaldo Calabresi. Cuando la viuda de Perón regresó al país, apoyó la aceptación de la propuesta del Vaticano y ello se ratificó en el Acta de Coincidencias firmada en el mes de junio. Dicha Acta de Coincidencias fue un acuerdo entre Alfonsín y María Estela Martínez de Perón. Ello incluyó impulsar en el Congreso una ley de amnistía especial para la expresidenta y a cambio ella regresó a Argentina para desautorizar la conducción partidaria de Lorenzo Miguel. Tal como afirma Horacio Verbitsky (2007), Alfonsín e Isabel firmaron junto con otros partidos políticos menores un Acta de Coincidencias que implicaba el acompañamiento al gobierno en temas conflictivos del momento: frente a la dura posición del FMI y los bancos acreedores en la negociación de la deuda externa, con respecto a la reticencia del Consejo Supremo de las Fuerzas Armadas a avanzar en el enjuiciamiento de las juntas militares, las resistencias generadas por la mediación papal en el conflicto con 
Chile por las islas sobre el canal Beagle, y la recomposición de relaciones con los sindicatos luego del rechazo por el Congreso de la ley de reordenamiento y democratización de las asociaciones profesionales. El Acta fue firmada por 16 partidos políticos; algunos de ellos

guardaron algunas reservas y otros directamente la rechazaron: la Unión del Centro Democrático (UCD), el Partido Comunista (PC), el Frente de Izquierda Popular (FIP) y el Partido Federal (PF) (Russell, 1984).

\section{Las reacciones políticas frente a la consulta popular}

El 25 de julio, el presidente Alfonsín anunció la convocatoria a la consulta popular. La estrategia alfonsinista fue recibida por el peronismo como una especie de "balde de agua fría”. Comenzaron los intensos debates en el bloque justicialista. La mayoría de los parlamentarios de ese partido estaban dispuestos a ejercer su rol opositor a través del cuestionamiento del preacuerdo desde distintas vertientes. Incluso, el 30 de julio los diputados miembros de la Comisión de Relaciones Exteriores de la Cámara se retiraron de la reunión con el canciller Dante Caputo en protesta por la determinación radical de imponer el carácter secreto y reservado a la conversación con el jefe del gobierno (Beagle. Aprestos parlamentarios, 1984). El 31 fijaron su posición oficial, haciendo hincapié en que solamente el Congreso de la Nación podía convocar por ley a una consulta popular, absteniéndose de rechazar la compulsa de opinión, pero sí calificando de autoritaria la actitud del Poder Ejecutivo nacional. De acuerdo a lo que afirmaba el diario Clarín, el peronismo solicitaba que la convocatoria del referéndum fuera por ley,

que tuviera carácter obligatorio e incluyera la renegociación de la deuda externa, su legitimidad o ilegitimidad y el rechazo o aceptación del convenio con el FMI, además de crear una comisión bicameral a fin de investigar los orígenes de la situación heredada. (Beagle. Aprestos parlamentarios, 1984, p. 6)

La cuestión de la consulta popular dividió aguas en un peronismo que aún no se recuperaba de la derrota electoral de 1983. Por lo tanto, fueron protagonistas de este episodio las diferencias interpartidarias.

A fines de agosto de 1984, el peronismo intentó evitarla, en una moción parlamentaria que no prosperó. El proyecto fue presentado por el senador José Humberto Martiarena, justificándolo en la supuesta inconstitucionalidad de la consulta popular, lesiva de la división de poderes. Consideraban que la consulta implicaba una derivación de las atribuciones del Poder Ejecutivo, algo constitucionalmente indelegable. El senador por Jujuy sostuvo que el decreto por el que se había convocado a la consulta "no puede considerarse derivado del 
artículo 33 de la Constitución" y que, aun admitiendo tal cosa, "ese mismo artículo permite remitirse al inciso 28 del artículo 67, que habla de las atribuciones del Congreso, y dice que es el encargado de hacer todas las leyes y reglamentos que sean convenientes" (Rechazo del proyecto peronista, 1984, p. 12). El voto por la negativa se debió a la posición de los bloques de las provincias de Corrientes, San Juan y Neuquén, que se plegaron al oficialismo. Al mismo tiempo, un juez federal de Río Gallegos, Federico Pinto Cramer, hizo lugar a un recurso de amparo presentado por Alberto Fonrouge, ex-apoderado del PJ de Buenos Aires, en que se solicitaba la anulación de la consulta por inconstitucional.

Por su parte, la Unión del Centro Democrático (UCeDé) y el Partido Comunista (PC) que paradójicamente habían rechazado el Acta de Coincidencias, aceptaron la iniciativa de la consulta popular. El comité del PC resolvió elevar ante el Congreso un proyecto para la firma de un protocolo adicional al tratado de límites, destinado a prohibir las actividades militares en la región austral y la explotación de los recursos económicos por parte de empresas extranjeras (Consulta sobre el Beagle: El PC decidió que votará por sí, 1984). En contrapartida, el Movimiento de Integración y Desarrollo (MID) y el Partido Federalista de Centro (FPC) se opusieron (Opiniones dispares sobre la consulta, 1984).

Mientras tanto, las negociaciones en la Santa Sede continuaban su curso. El 18 de octubre se firmó el acuerdo. El Acta de Protocolo fue rubricada por Delpech y por el coronel Ernesto Videla, jefe de la misión chilena. ${ }^{2}$ El documento estaba integrado por un cuerpo de 19 artículos que se refieren a la controversia limítrofe en la región y dos protocolos adicionales referidos a la solución de controversias bilaterales y a los acuerdos de navegación. Con respecto a la cuestión central, se establecía la soberanía chilena de las islas Nueva, Lennox y Picton y otros siete islotes, pero incluyó un reconocimiento del principio bioceánico, que implica la soberanía argentina en el Atlántico, limitando a su vez la soberanía marítima chilena a partir de las islas (Beagle: difunden el texto del acuerdo, 1984).

El presidente del bloque de senadores del justicialismo, Vicente Leónidas Saadi, fue el vocero de la posición oficial. Ahora, el peronismo estaba obligado a definir una posición clara respecto de la consulta y luego adoptar una decisión respecto de la ratificación parlamentaria del tratado. El debate se daba en un contexto en el que también estaba en disputa la dirección del PJ, en la cual el propio Saadi era partidario de una renovación que implicara posturas más críticas frente al gobierno radical. La cuestión del Beagle era el espacio propicio para ello (Un cambio de actitud, 1984).

2 La delegación argentina, presidida por Delpech, estaba conformada por Susana Ruiz Cerruti, Luis María Riqueri, el embajador Enrique Candiotti y el capitán de fragata Osvaldo Astiz. 
Haciendo énfasis en que podría tratarse de un "mal convenio" y en la falta de información, el peronismo llamó al "abstencionismo activo", al que nos referiremos. Por su parte, Ítalo Luder manifestó que, si bien había habido un mal manejo en la implementación de las tratativas de negociación por parte del gobierno, era parte de la plataforma electoral del PJ la idea de que "dentro de la mediación vaticana estaban las mejores condiciones para la solución pacífica con Chile". Uno de los cuatro secretarios generales de la Confederación General del Trabajo, Ramón Baldassini, destacó que la firma del tratado con Chile era un "verdadero acto de integración latinoamericana", instando a votar por el SÍ (Satisfacción y reserva en sectores partidarios, 1984, p. 6).

Óscar Alende, dirigente del Partido Intransigente, fue cauto, pero Rogelio Frigerio, del Movimiento Integración y Desarrollo (MID), expuso rápidamente su conformidad con el acuerdo firmado, al igual que lo hizo el excanciller Óscar Camilión, a pesar de que la posición oficial del partido sería otra.

El senador nacional por el PJ José Martiarena vinculó su posición a favor del NO, refiriéndose a que el acuerdo comprometía el principio bioceánico y, por lo tanto, implicaba una declinación de los derechos soberanos de Argentina en la zona austral. Las voces más duramente contrarias eran las de Saadi y Herminio Iglesias. Una cuestión central era cuánto podía alejarse el peronismo de la mediación papal, siendo que en el "Acta de Coincidencias" suscritas por Isabel Perón se había incluido el respaldo a dicha mediación. El argumento fue la falta de garantías al principio bioceánico y de la proyección argentina sobre la Antártida.

La cuestión de la soberanía de los territorios en litigio también fue defendida por estudiosos del Derecho Internacional, como es el caso del Dr. Alfredo Rizzo Romano, quien junto con otros juristas acusaba al gobierno de manejarse con debilidad negociadora, haciendo primar cuestiones de política interna.

Otros sectores del peronismo consideraban mejor votar por el SÍ como mal menor, porque se había llegado a una instancia de "callejón sin salida" en la negociación, pero no por ello restarse de plantear una crítica a las negociaciones y sus resultados. Era la posición del consejero Eduardo Vaca, por ejemplo (Debate en el peronismo, 1984). Incluso Juan Labaké también se inclinó por el Sí antes del pronunciamiento de María Estela Martínez de Perón. La ausencia de la presidenta del partido dificultaba la decisión. Entre otras razones, ello llevó a pensar la estrategia de conformar la designación de un consejo provisorio del PJ, para preparar la reorganización del peronismo (Entre el sí y la abstención, 1984). Julio Bárbaro, diputado nacional por el Partido Justicialista, se había proclamado en septiembre de 1984 a favor del acuerdo, utilizando dos argumentos centrales: terminar con el falso "patriotismo" vinculado con el autoritarismo de la dictadura militar, donde la cuestión del Beagle marcaba 
"la línea divisoria entre un país en ruinas, dividido y marchito y un proyecto de futuro que sin el lastre de sueños irrealizables nos permita alcanzar el despegue argentino. Un país posible, sin fraudes, ni delirios" (Bárbaro, 1984, p. 14). Y, en segundo lugar, la importancia de evitar el conflicto con países hermanos latinoamericanos.

Nuestro enfrentamiento con Chile no responde a causas enraizadas en los respectivos pueblos. Por el contrario, en las actuales circunstancias, después de la guerra de Malvinas, un acuerdo serio con el país trasandino nos permitirá dedicar todas nuestras energías al tema de las islas atlánticas. Porque nuestro verdadero enemigo no está en el otro lado de frontera, como se ha probado más de una vez, sino en los imperialismos de turno, que -como se vio en Malvinas- no titubean para aunar sus fuerzas cuando se trata de aplastar a un país dependiente. (Bárbaro, 1984, pp. 14-15)

Por último, en la misma nota había un mensaje a otros representantes de su partido, al afirmar la tradición pacifista del peronismo, y la necesidad de continuar en esa línea para alcanzar la unidad latinoamericana, que consideraba primordial: "[...] Algunos de sus seguidores parecen no haber comprendido su mensaje" (Bárbaro, 1984, p. 15).

El 30 de octubre, a través de un documento, el peronismo dio a conocer su posición oficial fundamentando que el hecho de la realización de la consulta debilitaba el margen de negociación de los representantes argentinos (El peronismo decidió abstenerse en la cuestión del Beagle, 1984). Fundamentalmente, se afirmaba que el apuro del gobierno por cerrar el tratado constituía un problema para llegar a la mejor solución. El llamado a la "abstención masiva y militante" incluía una campaña nacional de concientización y fue decidido "sin conocerse la opinión de María Estela Martínez de Perón”, tal como reconocía Adolfo Ponce, diputado del PJ encargado de anunciar la posición oficial. El objetivo del peronismo era demostrar que, según sus términos, la consulta popular buscaba distraer "en momentos en que el conjunto de la sociedad argentina atraviesa una grave crisis económica" (Beagle: pide el justicialismo que siga la mediación papal, 1984, pp. 2 y 3). Tal como se había anticipado, Luder se pronunció aconsejando el voto afirmativo a pesar de las críticas a la gestión, aparentemente también en línea con Lorenzo Miguel (Ítalo Luder aconsejó el voto afirmativo, 1984).

La cuestión de la abstención pretendía distanciarse políticamente del radicalismo, sin caer en similitudes con una derecha enfáticamente opositora a la mediación. En efecto, a partir del documento del PJ, el almirante Rojas invitó al presidente Alfonsín, a través de una carta, a mantener un debate público al respecto y afirmó que el peronismo estaba "enarbolando la bandera nacional y patriótica que corresponde" y que se sentía "muy satisfecho de esa actitud 
y hasta podría entrar en conversación con los dirigentes justicialistas" (Rojas desafía, 1984, p. 4).

El debate con gran parte del peronismo demostraba la prioridad de la lógica partidaria electoral más que una discusión sobre cuestiones jurídicas, geográficas o geopolíticas. Según el diario Clarín, Lorenzo Miguel intentó evitar la posición abstencionista porque ella implicaba asumir el riesgo de una nueva derrota electoral si predominaba la actitud concurrencista y el voto afirmativo el 25 de noviembre (Un cambio de actitud, 1984).

El debate público más recordado es el que enfrentó a Caputo con Saadi, que fuera transmitido por radio y televisión (canal 7 y canal 13) y conducido por Bernardo Neustad, a una semana de la elección. Allí se plantearon claramente los argumentos a favor y en contra del Sí. La campaña del oficialismo culminó con un acto multitudinario en la cancha de Vélez Sarsfield, cuyo orador de fondo fue Dante Caputo. La preocupación del gobierno, más que la decisión de los votantes, era el abstencionismo, porque en ese caso representaría un fracaso político para el radicalismo.

El gobierno logró instalar la discusión en términos de democracia vs. dictadura. Un clivaje que ya había sido fundamental para el triunfo electoral de 1983, con la denuncia del pacto militar sindical, y con la caracterización del peronismo como movimiento antidemocrático a partir de la famosa quema del cajón que había tenido a Herminio Iglesias de protagonista. Esa discusión entregaba cualquier tipo de reivindicación nacional a una versión autoritaria. Es decir, abonaba la confusión y una falsa fusión entre los reclamos soberanos y el autoritarismo. Una gráfica que cubrió la ciudad era representativa de esa estrategia: un cartel mostraba una enorme granada de mano que contenía fotos de todos los personajes políticos y militares que no apoyaban el SÍ, bajo un título que decía: "Desactívela". Entre ellos aparece el controvertido dirigente peronista Iglesias (Ares, 1984, s/p.).

Como anticipábamos, el temor del gobierno no era el triunfo del Sí, sino el porcentaje de votantes. Un alto nivel de abstencionismo sería considerado una derrota respecto de la legitimidad del alfonsinismo. Algunos autores han considerado que el presidente radical afrontó en esta oportunidad uno de los debates públicos más polémicos de la historia argentina (Church, 2008) porque, en efecto, se vinculaba con la gestión económica y el juzgamiento de los militares responsables de las peores violaciones a los derechos humanos. La última semana de campaña, Alfonsín, que retomaba el tono enérgico de la campaña electoral, habló desde los balcones del palacio legislativo en la ciudad de La Plata, capital de la provincia de Buenos Aires. Cuestionó fuertemente la abstención en la consulta propuesta por el peronismo "porque si votan pocos se han de alegrar los partidarios de la violencia y la dictadura en la Argentina" (Ares, 1984). El hecho de que los militares retirados se 
posicionaran claramente por el NO, alimentaba esa fractura. Zurita (2014) sugiere la hipótesis de que los militares en servicio fueron más cautos, dado su complejo y nuevo rol en el contexto democrático.

Un elemento central que abogaba por el éxito de la propuesta era la relevancia de los vínculos con la Iglesia Católica, presentes en fuerzas políticas diversas. Ya había quedado de manifiesto con la posición de Frondizi y de Isabel Perón, y se expresaría también dentro del peronismo en el caso de Jorge Triaca, uno de los cuatro secretarios generales de la CGT unificada. Incluso, cuando el dirigente declaró que el llamado a la consulta era un hecho electoralista, afirmó que:

La intervención del Santo Padre no se discute en absoluto, lo que uno plantea son las circunstancias políticas internas que se entremezclan en una decisión de esta gravitación y naturaleza. Somos contrarios a la consulta ciudadana convocada por el gobierno. (El Acuerdo por el Beagle: reacciones locales, 1984, p. 8)

El plebiscito se realizó el domingo 25 de noviembre de 1984. La participación fue muy alta, de un 70,09\% de la población. El SÍ triunfó ampliamente, por un 82,60\% a nivel nacional, imponiéndose frente al NO en todas las provincias argentinas (Lacoste, 2004). El gobierno mostraba éxito en sus objetivos, dejando poco margen a los parlamentarios para oponerse a la ratificación del acuerdo en el recinto.

A pesar de ello, la votación en la Cámara de Senadores para su ratificación, en el mes de marzo de 1985, no fue sencilla. Duró 24 horas y el acuerdo se aprobó con 23 votos a favor, 22 en contra y la abstención del senador radical Luis León, quien en el momento de la votación abandonó el recinto. Los 22 votos en contra eran de los 21 senadores del Partido Justicialista y de Elías Sapag, legislador del Partido Popular Neuquino (La Cámara de Senadores ratificó el Tratado sobre el Beagle, 1985).

La argumentación del senador León incluyó una fuerte crítica a Pinochet y al comportamiento internacional de Chile respecto de la región. Afirmó "este tratado es en el fondo el sueño realizado de Pinochet", "Chile siempre esperó que tuviésemos problemas para apuñalarnos por la espalda", y "antes de hablar de integración latinoamericana, la Argentina debe exigir que Chile devuelva las costas que le robó a Bolivia” (El Senado sancionó el acuerdo, 1985, p. 10). Del lado vecino, el 11 de abril de 1985, la junta militar de la dictadura chilena ratificó el tratado (Lavopa, 1995). 


\section{Derechas e izquierdas}

Nos hemos referido ya a la posición de Rojas y de Lanusse. Falta agregar a ese cuadro que, mientras avanzaban las negociaciones en el Vaticano, particularmente los militares retirados se fueron mostrando cada vez más abiertamente en desacuerdo, tal como lo plantea Zurita (2014) en su trabajo al respecto. Uno de ellos, quien se desempeñaba como jefe de la delegación argentina, general Ricardo Etcheverry Boneo, renunció por disconformidad con el avance de la propuesta papal. Etcheverry Boneo había sido nombrado jefe de delegación por el general Videla, y a partir del protagonismo asumido por el embajador Mario Delpech, subsecretario de Asuntos Limítrofes, y del curso que habían adoptado las negociaciones en el Vaticano, Alfonsín le aceptó la renuncia el 19 de julio (Beagle: dimitió Etcheverry Boneo, 1984).

En la misma línea se expresó en ese contexto Luciano Benjamín Menéndez -a cuya participación en el boicot al Acta de Montevideo ya nos hemos referido-, utilizando como argumento central la cuestión de la lesión del principio bioceánico. Como miembro de la agrupación Movimiento por la Soberanía, elaboró un documento crítico de la mediación, indicando que la máxima cesión posible era la de trazar el límite de la zona, conservando para Argentina la soberanía de las islas Nueva, Evout, Barnevelt, Decelt y la porción de la isla de Hornos al oriente de la divisoria que materializa el Meridiano de Hornos (Cuestiona Menéndez el acuerdo con Chile, 1984). Otras agrupaciones también vinculadas con la corporación militar se expresaron en contra. Entre ellas figuraban el Instituto Argentino de la Soberanía, presidido por el capitán de ultramar Luis Noziglia; el Movimiento de Beagle y Atlántico Sur, liderado por el almirante retirado Rojas, y el Círculo de Estudios del Movimiento Humanista Argentino, encabezado por el general retirado Roberto Levingston. El teniente general también retirado Juan Carlos Onganía, militar golpista, entregó un comunicado a la prensa con una posición profundamente antidemocrática. Acusaba a la decisión presidencial de realizar una consulta como una "frivolidad", llamando a la abstención, asociando este tipo de prácticas de democracia participativa con las "dictaduras colectivistas" (1984: Consulta popular por el Beagle, 2012, s/p.).

El Movimiento al Socialismo realizó un congreso nacional en el mes de julio y formuló una fuerte crítica al gobierno de Alfonsín, tanto en aspectos políticos como económicos. En esa oportunidad, elaboró una circular interna en la que se afirmaba que la consulta sobre el diferendo por el Beagle era una "cortina de humo para distraer la atención del pueblo de los verdaderos problemas del país agravados por los desastres políticos económicos y sociales que está produciendo el mismo gobierno: prometió no pagar la deuda con el hambre del pueblo y la está pagando con ella y la entrega del país" (MAS, 1984, s/p). Por otra parte, se impugnaba el acuerdo con la dictadura de Pinochet, considerando que se trataba de una 
"ratificación de la siniestra política internacional del gobierno de Alfonsín que sostiene que los acuerdos diplomáticos de las dictaduras genocidas son válidos y exigibles" (MAS, 1984, $\mathrm{s} / \mathrm{p})$.

Con respecto a la situación internacional, claramente el documento se mostraba a favor de la paz con Chile desde una perspectiva antiimperialista. La consigna finalmente fue "Repudie al gobierno de Alfonsín. No a la firma del Tratado con Pinochet. Sí a la paz con Chile. Exigimos una consulta popular sobre el acuerdo con el FMI". El Frente de Izquierda Popular ordenó a sus afiliados una abstención militante, similar a la del peronismo. La Juventud del Trabajo y el Partido del Trabajo y el Pueblo (PTP) llamaron a votar por la afirmativa, a pesar de marcar claras diferencias con el gobierno nacional. El argumento central era la importancia de resolver el conflicto con un país hermano en el contexto de la rivalidad entre las potencias por el predominio en la región.

En momentos en que la disputa entre las dos superpotencias lleva al mundo al abismo de una tercera guerra mundial; en momentos en que nuestro país, parte de ese Tercer Mundo oprimido y saqueado por las dos superpotencias, transita la crisis más terrible de su historia [...] el PTP levanta esta tribuna para llamar a la clase obrera, al pueblo y a todos los patriotas realmente interesados en defender los intereses nacionales y populares, a movilizarse para garantizar un sí rotundo y masivo a la propuesta papal, que rubrique, con la fuerza que sólo puede dar la movilización popular, una paz definitiva con el hermano pueblo de Chile. Eso será sin duda un gran triunfo de la lucha antiimperialista y tercermundista de nuestro pueblo, y de todos los pueblos del mundo que enfrentan el expansionismo y el guerrerismo de las superpotencias. (Nassif, 1984, s/p)

\section{Conclusiones}

Haciendo un seguimiento y análisis de las posiciones y argumentos políticos presentados por distintas fuerzas y corrientes respecto del referéndum por el caso del Beagle, podemos sintetizar que hubo distintas variables centrales que ordenaron el posicionamiento.

1) La lectura de la situación en clave de política interna: no legitimar la propuesta del gobierno.

2) El peso político de la Iglesia Católica y las vinculaciones que tenía en dirigentes de distintas fuerzas políticas.

3) En clave, rivalidad con países vecinos, basada en un nacionalismo de carácter autoritario y antidemocrático. Utilización de la noción de soberanía en esos términos.

4) La relación con la dictadura de Pinochet. 
5) En el marco del "giro realista" y la vinculación con las Malvinas (la desmalvinización).

6) Una lectura sobre la rivalidad de las potencias en la región, basada en un nacionalismo de carácter antiimperialista.

Para el oficialismo, solucionar el diferendo por el Beagle respondía tanto a la convicción de la necesidad de resolver pacíficamente el conflicto, como a la necesidad de presentar a una Argentina de valores democráticos frente a la comunidad internacional. Ese último elemento se vinculaba también con la estrategia de giro realista, ya que arribar a dicha solución aparecía como "ejercicio de una política exterior predictible y confiable capaz de superar las desconfianzas existentes en el Norte" (Russell, 1984, p. 337). En la nueva orientación realista del oficialismo se expresan dos cuestiones centrales para nuestras conclusiones.

La primera es la vinculación entre el conflicto del Beagle y las Malvinas. Claramente se trata de dos hechos que tienen relación en el proceso histórico, tal como a su vez lo ratifican documentos recientemente desclasificados. Sin embargo, en términos de la política exterior argentina, la primera de las cuestiones refiere a un problema limítrofe con un país vecino, mientras que la segunda remite a la existencia de un enclave colonial en el Atlántico Sur, que afirma el dominio de Gran Bretaña sobre territorio argentino. En el primero de los casos, los argumentos vinculados a la soberanía y a la tradición autoritaria de la geopolítica fueron utilizados por sectores de las Fuerzas Armadas que, cuando participaron ilegítimamente del gobierno en cuestiones de agenda económica, no dudaron en someter sus decisiones a imposiciones de potencias extranjeras, como es el caso de los gobiernos de Aramburu, en el que Rojas se desempeñó como vicepresidente, el de Lanusse, o como el de Onganía. En el segundo, la cuestión de lo nacional cobra otro carácter, en tanto incluye una reivindicación genuina respecto de la injerencia de una potencia extranjera. Así, el reclamo no solamente podía ser defendido en la clave de ese nacionalismo autoritario y de rasgos fascistas, sino de un nacionalismo de base antiimperialista.

Con la vinculación que el gobierno hacía de ambas situaciones, y con la necesidad de presentar una Argentina democrática como sinónimo de "no conflictiva" para las potencias, no solamente cumplía su lógico y muy justificado objetivo de quitar legitimidad a los reclamos autoritarios y chauvinistas de muchos sectores, en especial de los militares retirados, sino que también atentaba contra los argumentos válidos del antiimperialismo, abonando lo que luego sería la etapa de "desmalvinización" en el marco del giro realista.

Recordemos que a partir de 1985 el período fue caracterizado como de desmalvinización, porque el tema fue prácticamente dejado fuera de la agenda de política exterior del gobierno -a pesar de que se continuó con una estrategia multilateral en la Asamblea General de 
Naciones Unidas y otros foros internacionales. Mientras tanto, Gran Bretaña desarrolló una política de hechos consumados: había logrado en mayo de 1985 una base militar permanente con pista de aterrizaje, una zona de administración y conservación pesquera de 150 millas en febrero de 1987 como reacción a los acuerdos pesqueros realizados por Argentina con Bulgaria y la Unión Soviética, y había realizado maniobras militares en marzo de 1988, e instalado una línea marítima regular entre las islas Malvinas y los puertos de Montevideo y Punta Arenas.

En síntesis, ambos conflictos eran heridas abiertas que la última dictadura dejaba a la naciente democracia. Pero los contenidos eran distintos, y el tipo de actores involucrados también lo era. El giro realista y el tránsito hacia políticas cada vez más acordes a los dictámenes de las potencias y organismos internacionales de crédito fue justificado a través de la impugnación de todo rasgo de nacionalismo, atentando también contra toda afirmación autonómica, en particular aquellas de carácter antiimperialista, expresión de corrientes ideológicas con trayectoria histórica en la Argentina.

\section{Referencias}

Alfonsín, R. R. (1984). Discurso pronunciado por el Sr. Presidente de la Nación Doctor Raúl Ricardo Alfonsín con motivo de la visita del señor presidente de los Estados Unidos Mexicanos, Miguel de la Madrid Hurtado, el día 3 de abril de 1984. Discursos Presidenciales. Buenos Aires: Secretaría de Prensa de la Presidencia de la Nación.

Ares, C. (22 de noviembre de 1984). Alfonsín participa en la campaña del referéndum sobre el canal de Beagle. El País. Recuperado de https://elpais.com/diario/1984/11/22/internacional/469926008_850215.html

Apreciaciones del almirante Rojas (24 de enero de 1984). La Nación, p. 2.

Argentina y Chile firmaron en Roma la declaración de Paz y Amistad (24 de enero de 1984). Tiempo Argentino, p. 7.

Bárbaro, J. (9 de marzo de 1984). El Beagle y los patriotas. Clarín, pp. 14-15.

Beagle. Aprestos parlamentarios (19 de octubre de 1984). Clarín, p. 6.

Beagle: difunden el texto del acuerdo (19 de octubre de 1984). Clarín, pp. 2 y 3. 
Beagle: dimitió Etcheverry Boneo (20 de julio de 1984). Clarín, p. 6.

Beagle: pide el justicialismo que siga la mediación papal (31 de octubre de 1984). Clarín, pp. 2 y 3.

Benadava, S. (1999). Recuerdos de la mediación pontificia entre Chile y Argentina (19781985). Santiago de Chile: Universitaria.

Bonnet, A. (2007). La hegemonía menemista. El neoconservadurismo en la Argentina 19892001. Buenos Aires: Prometeo.

Caputo: expresión de auténtica esperanza (24 de enero de 1984). La Nación, p. 3.

CIA RECORDS (8 de diciembre de 1979). Alert Memorandum. From de Director of Central Intelligence to National Security Council. Subject: Beagle Channel dispute and the potential for conflict. CIA FOIA Collection Document Number 0005617746. Recuperado de http://www.dtic.mil/dtic/tr/fulltext/u2/a163393.pdf

Consulta sobre el Beagle: el PC decidió que votará por sí (1 de noviembre de 1984). Clarín, p. 13.

Cuestiona Menéndez el acuerdo con Chile (20 de julio de 1984). Clarín, p. 6.

Church, J. M. (2008). La crisis del canal del Beagle. Estudios Internacionales, 161(41), 733.

Dante Caputo: rechazo a la política de poder (24 de enero de 1984). Tiempo Argentino, p. 7.

Debate en el peronismo (24 de octubre de 1984). Clarín, p. 8.

De Riz, L. y Smulovitz, C. (1991). Instituciones y dinámica política. El presidencialismo argentino. En D. Nohlen y L. De Riz (Comps.), Reforma institucional y cambio político (pp. 137-157). Buenos Aires: Legasa, CEDES.

Discurso de Dante Caputo en el almuerzo anual de la Cámara de Anunciantes (3 de agosto de 1984). La Nación, p. 3.

El Acuerdo por el Beagle: reacciones locales (22 de octubre de 1984). Clarín, p. 8. 
El compromiso de paz con Chile: respaldo y críticas (25 de enero de 1984). Clarín, p. 4.

El peronismo decidió abstenerse en la cuestión del Beagle (30 de octubre de 1984). Clarín, p. 3 .

El Senado sancionó el acuerdo (15 de marzo de 1985). La Nación, p. 10.

Entre el sí y la abstención (25 de octubre de 1984). Clarín, p. 19.

Fair, H. (2009). La dinámica del sistema político durante el gobierno de Alfonsín. Temas y Debates. Revista Universitaria de Ciencias Sociales, 17, 35-68.

Ítalo Luder aconsejó el voto afirmativo (31 de octubre de 1984). Clarín, p. 3.

La Cámara de Senadores ratificó el Tratado sobre el Beagle (15 de marzo de 1985). La Nación, p. 1.

La propuesta del Papa Juan Pablo II (24 de enero de 1984). Tiempo Argentino, p. 3.

Lacoste, P. (2003). La imagen del otro en las relaciones de la Argentina y Chile (1534-2000). Buenos Aires: Fondo de Cultura Económica.

Lacoste, P. (2004). La disputa por el Beagle y el papel de los actores no estatales argentinos. Universum, 19(1), 86-109. Recuperado de https://dx.doi.org/10.4067/S071823762004000100005

Lavopa, J. H. (1995). Las relaciones argentino-chilenas. Política económica, exterior y de defensa. La influencia de los grupos de presión desde el Tratado de Paz y Amistad de 1984. Buenos Aires: CARI-Fundación Konrad Adenauer.

Lanús, A. (1984). De Chapultepec al Beagle: política exterior argentina (1949-1980). Buenos Aires: Emecé.

MAS. Movimiento al Socialismo (Agosto, 1984). Congreso del MAS. Resolución del Comité Nacional sobre la Consulta Popular por el diferendo del Beagle (Circular interna $\mathrm{N}^{\circ}$ 63, s/p.). Buenos Aires: Movimiento al Socialismo.

Míguez, M. C. (2013). Partidos políticos y política exterior argentina. Buenos Aires: Ariel. 
Nassif, R. (1984). Discurso pronunciado en la Federación Argentina de Box. Recuperado de http://pcr.org.ar/nota/unidad-a-los-pueblos-argentino-y-chileno-junto-al-tercermundo/

Opiniones dispares sobre la consulta (4 de agosto de 1984). Clarín, p. 8.

Optimismo de Caputo por la solución con Chile (24 de enero de 1984). La Nación, pp. 1 y 4.

Oposición a un arreglo con Chile sin que haya debate previo (2 de enero de 1984). La Nación, p. 5.

Paradiso, J. (1993). Debates y trayectorias de la política exterior argentina. Buenos Aires: Grupo Editor Latinoamericano.

Rechazo del proyecto peronista (23 de agosto de 1984). La Nación, p. 12.

Reficco, E. (1996). Política exterior y cultura política: el caso de la democracia argentina (1983-1995). Revista CIDOB d'Afers Internacionals, (32), 65-97.

Resonancia favorable en el Senado nacional (23 de enero de 1984). La Nación, p. 4.

Rojas desafía (30 de octubre de 1984). Clarín, p. 4.

Russell, R. (1984). El diferendo austral: Posiciones divergentes. América Latina/Internacional, 2(1), 19-34.

Russell, R. (1990). Política exterior y toma de decisiones en América Latina: aspectos comparativos y consideraciones teóricas. En R. Russell (ed.), Política exterior y toma de decisiones en América Latina (pp. 255-274). Buenos Aires: RIAL.

Satisfacción y reserva en sectores partidarios (31 de octubre de 1984). Clarín, p. 6.

Tapia, L. A. (1997). Esta noche: la guerra. Viña del Mar, Chile: Ediciones de la Universidad Marítima de Chile.

Un arbitraje nulo de nulidad absoluta (24 de enero de 1984). Tiempo Argentino, p. 3.

Un cambio de actitud (31 de octubre de 1984). Clarín, p. 4. 
Verbitsky, H. (11 de febrero de 2007). El pacto Alfonsín-Isabel. Página 12. Recuperado de https://www.pagina12.com.ar/diario/elpais/1-80241-2007-02-11.htm

Videla Cifuentes, E. (2008). La desconocida historia de la mediación papal, diferendo austral Chile-Argentina 1977-1985. Santiago: Ediciones Universidad Católica.

Zurita, M. D. (2014). Democracia y política exterior: Fuerzas Armadas y funcionarios alfonsinistas a 30 años de la consulta popular por el Beagle. VIII Jornadas de Sociología de la Universidad Nacional de La Plata. Recuperado de http://www.memoria.fahce.unlp.edu.ar/trab_eventos/ev.4239/ev.4239.pdf

1984: Consulta popular por el Beagle (16 de diciembre de 2012). Diario del Centro del País, Coleccionable Transitando los caminos de la historia Nota $N^{o} 321$. Recuperado de http://anteriores2.wfxgroup.com.ar/noticias/nota.asp?nid=60271

Cómo citar este artículo: Míguez, M. C. (2018). El Canal Beagle y consulta popular en 1984. Relaciones internacionales y política interna argentina. Si Somos Americanos. Revista de Estudios Transfronterizos, 18(2), 78-102. 